\title{
Value of Intraoperative Monitoring of the Trigeminal Nerve in Detection of a Superiorly Displaced Facial Nerve During Surgery for Large Vestibular Schwannomas
}

\author{
Yasmine A. Ashram \\ Alexandria University \\ Youssef M. Zohdy \\ Alexandria University \\ Tarek A. Rayan \\ Alexandria University \\ Mohamed M.K. Badr-El-Dine ( $\square$ mbeldine@yahoo.com ) \\ Alexandria University Faculty of Medicine https://orcid.org/0000-0001-6480-6538
}

\section{Research Article}

Keywords: Electromyography, Facial nerve, Facial nerve displacement, Intraoperative monitoring, Trigeminal nerve, Vestibular schwannoma

Posted Date: March 26th, 2021

DOI: https://doi.org/10.21203/rs.3.rs-323289/v1

License: (c) (1) This work is licensed under a Creative Commons Attribution 4.0 International License. Read Full License

Version of Record: A version of this preprint was published at Neurosurgical Review on September 17th, 2021. See the published version at https://doi.org/10.1007/s10143-021-01646-7. 


\section{Abstract}

Objective

To investigate the role of trigeminal and facial nerve monitoring in the early identification of a superiorly displaced facial nerve.

Patients and Methods

This prospective study included 24 patients operated for removal of large vestibular schwannomas (VS). Electromyographic (EMG) events recorded after mapping the superior surface of the tumor were evaluated by analyzing the latencies of the responses from the masseter and facial nerve innervated muscles.

Results

The latency of the recorded compound muscle action potential (CMAP) from the masseter muscle was $3.6 \pm 0.5 \mathrm{msec}$, and of the simultaneously recorded volume conducted responses from the frontalis, o.oculi, nasalis, o.oris and mentalis muscles were $4.6 \pm 0.9,4.1$ $\pm 0.7,3.9 \pm 0.4,4.3 \pm 0.8$ and $4.5 \pm 0.6 \mathrm{msec}$ respectively after trigeminal nerve stimulation in $24(100 \%)$ patients. In $6(25 \%)$ patients, the mean latency of CMAP on the masseter was $3.6 \pm 0.5 \mathrm{msec}$, and the latencies of the CMAP from the frontalis, nasalis, o.oris and mentalis muscles were longer than those of the volume conduced responses $(p=0.002 ; p=0.001 ; p<0.001 ;$ and $p=0.015$ respectively) indicating stimulation of both nerves (trigemino-facial EMG response). All patients with this response were later confirmed anatomically to have an AS displaced facial nerve.

Conclusion

Understanding the trigemino-facial EMG response is of value in identifying an AS displaced facial nerve; in preventing electrophysiological confusion between the trigeminal and the facial nerves; and in detecting the presence of volume conducted contributions in the measured facial nerve CMAP at the end of surgery.

\section{Introduction}

Intraoperative monitoring of the trigeminal nerve during vestibular schwannoma (VS) surgery is relatively understated, as it is generally less likely to be injured during tumor resection than the facial nerve [10]. Nevertheless, the motor division of the trigeminal nerve is usually monitored during surgical removal of large tumors that may grow to involve the nerve; and distort regional anatomy [17, 12].

Despite the recent introduction of new techniques to monitor both the facial and trigeminal nerves such as transcranial corticobulbar motor evoked potentials (CoMEPs) and intraoperative blink reflex, the most commonly used modalities for monitoring both nerves are still a combination of free-run and triggered electromyography (EMG) $[1,7,8,13,22]$. Triggered EMG may be required for the electrophysiological distinction between the facial and the trigeminal nerves in the early stages of tumor resection before the anatomical differentiation is possible. Using a multichannel recording setup, stimulation of the motor axons of the trigeminal nerve produces a compound muscle action potential (CMAP) on the masseter and/or temporalis muscle and often simultaneously recorded volume conducted responses from one or more facial nerve monitoring channels. Such volume conducted responses are due to peripheral spread of activity from the contracting trigeminal nerve innervated, to the nearby facial nerve innervated muscles [23]. Similarly, stimulation of the facial nerve yields a response from the facial nerve monitoring channels, with the possibility of recording simultaneous volume conducted responses from the masseter and/or the temporalis muscles, because of the proximity of the contracting facial nerve innervated muscles to those innervated by the trigeminal nerve [17]. Despite the possibility of recording volume conducted responses, identifying which nerve is being stimulated is usually straight forward if the latencies of the recorded CMAPs is analyzed. When the trigeminal nerve is stimulated a CMAP is recorded from the masseter and /or temporalis muscles having a latency less $5 \mathrm{msec}(3-4 \mathrm{msec})$ and the volume conducted responses from the facial nerve monitoring channels will be recognized by having a shorter latency than that of facial nerve stimulation [23]. Furthermore, stimulation of the facial nerve yields a CMAP having a latency of about between 6-8 msec (differs according to the exact site of stimulation) recorded from the facial nerve innervated muscles, and the possible volume conducted responses recorded from the trigeminal nerve monitoring channels will have a longer latency than that of trigeminal nerve stimulation $[3,17,23]$. However, one exception to this rule occurs in some patients with large tumors and facial neve displacement.

As the tumor increases in size the course of the facial nerve may be displaced into unpredictable patterns depending on the direction of growth. The displacements are classified into posterior (P), towards the dorsal surface of the tumor which is quite rare (2\%); anterior and central (AC); anterior and inferior (Al); and anterior and superior (AS) patterns $[9,16]$. When the facial nerve is displaced in an AS direction 
it becomes anatomically closer to the trigeminal nerve which can make the electrophysiological differentiation between both nerves even more challenging. This is especially true if the two nerves are close enough to be simultaneously stimulated when mapping the superior surface of the tumor. This situation produces a characteristic EMG response which if recognized would avoid further electrophysiological confusion between both nerves and could be used as an early predictor of an AS course of the facial nerve. The earlier recognition of the facial nerve course in large tumors may influence the surgical strategy, extent of resection, and facial nerve outcome. The aim of this prospective study was to characterize a triggered EMG response for the identification of an AS displaced facial nerve close to the trigeminal nerve before it becomes visible in the surgical field, and to discuss the implications of this response.

\section{Methods}

\section{Study sample}

Among 46 patients who underwent surgery for resection of VS between January 2017 and April 2019, 26 patients with tumor size of more than $30 \mathrm{~mm}$ (Koos stage IV) were included in this prospective study [14]. Tumor size was measured according to the maximum diameter of its extra-meatal component displayed on preoperative MRI axial view. Two patients experienced interruption of the facial nerve during surgery and were later excluded. The remaining population consisted of 24 patients of which preoperative facial function was assessed as Grade I in 21 patients (87.5\%), and Grade II in 3 patients (12.5\%) using the House and Brackmann (HB) grading system [11].

This study was approved by the institutional ethical committee, and an informed consent was obtained from all patients before being enrolled in the study.

\section{Intraoperative neurophysiological monitoring}

A multichannel protocol was used to monitor the facial nerve with sterile bipolar non-insulated $13 \mathrm{~mm}$ long needle electrodes inserted into the frontalis, orbicularis oculi (o.oculi), nasalis, orbicularis oris (o.oris) and mentalis muscles [2]. A non-insulated $18 \mathrm{~mm}$ bipolar electrode was also inserted into the trapezius muscle to monitor the accessory nerve. In addition, a sterile paired Prass needle that is insulated except at the tip to avoid cross stalk innervation between the facial and trigeminal nerve innervated muscles (Medtronic xomed Jacksonville, FL, USA), was placed into the masseter muscle to monitor the trigeminal nerve [23]. Free-run and triggered EMG, as well as CoMEPs were used to monitor the facial, trigeminal and accessory nerves for all patients, but data were not analyzed for this study. Once the tumor was exposed, triggered EMG was used to map the surface of the tumor before starting resection to exclude a dorsal course of the facial nerve. Electric stimulation was performed using a monopolar flush tip probe, with a needle electrode inserted at the edge of the wound used as a reference. The stimulator delivered constant current pulses at a rate of $7.1 \mathrm{pulse} / \mathrm{sec}$ with a stimulus duration of 200 $\mu \sec [3]$.

Tumor debulking progressed meticulously until the surgeon could reach the superior surface of the tumor. Mapping of the superior surface was then done using the same stimulus parameters and a current intensity between 0.2 and $0.4 \mathrm{~mA}$, aiming to stimulate the trigeminal nerve as well as to identify a possible superior course of the facial nerve. Higher current intensities were not used to avoid current spread and possible stimulation of a facial nerve that is not directly at the superior surface of the tumor; and because the volume conducted responses increase in amplitude and frequency as the current intensity increases.

The latency of the recorded CMAP from the masseter muscle as well as from each of the facial nerve monitoring channels with each response pattern was measured and analyzed in real time after stimulation of the superior surface of the tumor. Using a multichannel recording setup, a response recorded from any of the facial nerve monitoring channels having a latency of 7 msec or more was defined as a CMAP to facial nerve stimulation, while a response having a latency of less than $6 \mathrm{msec}$ from any of the facial nerve monitoring channels was defined as a volume conducted response associated with trigeminal nerve stimulation. A response recorded from any of the facial nerve monitoring channels having a latency between 6 and $6.99 \mathrm{msec}$ was considered equivocal and was not used for analysis. Similarly, responses recorded from the masseter muscle having a latency less than $5 \mathrm{msec}$ were defined as CMAPs to trigeminal nerve stimulation, while responses having a latency of $5 \mathrm{msec}$ or more were defined as volume conducted responses associated with facial nerve stimulation. Events recorded after stimulation of the superior surface of the tumor were evaluated by analyzing the latencies of the facial nerve responses in context with the latency of the responses from the masseter muscle.

Later in the course of dissection, stimulation of the facial nerve was performed near its root exit zone as soon as it was exposed as well as at the end of dissection to determine the threshold; the amplitude and latency of responses to supramaximal stimulation at $2 \mathrm{~mA}$ for each recording muscle.

Neurophysiological monitoring was performed using (Cadwell elite Laboratories, Inc., Kennewick, Washington, United States).

Page $3 / 12$ 


\section{Anesthesia and surgical technique}

All patients were operated on in the lateral position through the retrosigmoid approach, using total intravenous anesthesia (propofol and fentanyl infusion) with no muscle relaxant except at induction.

If an AS course of the facial nerve was identified by electric stimulation, the surgeon became well oriented about the anatomical relations and proceeded in the tumor removal away from the expected facial nerve. If there was no electrophysiological evidence of a superiorly displaced facial nerve, this would increase comfort during early stages of dissection by limiting the displacement possibilities between AC and Al. Piecemeal tumor removal progressed, once the course was anatomically identified dissection followed the facial nerve towards the porus of the IAC. This is the site of maximal adhesion and thinning of the facial nerve over the tumor capsule. The porus as well as the medial 2/3 of the posterior wall of the IAC were drilled out to complete tumor resection from the fundus of the IAC. Endoscopic check of the fundus was regularly used when in doubt of leaving residual tumor deep in the fundus.

Removal of the intrameatal component of the tumor and identification of the facial nerve in the IAC facilitated the dissection along the length of the facial nerve. Continuous facial nerve Stimulation and monitoring were performed during this stage of surgery as this is the most critical dissection until removal of the last piece of tumor is achieved. It is at this stage and based on the degree of splaying, adhesions, and the EMG responses during dissection that determined the final degree of tumor removal whether total, near-total or subtotal.

\section{Postoperative follow-up}

Immediate postoperative assessment of facial nerve function was performed by clinical examination using the HB grading system on the second postoperative day, then follow up late evaluation at 9-12 months postoperative.

\section{Statistical analysis of the data}

Data were fed to the computer and analyzed using IBM SPSS software package version 20.0. (Armonk, NY: IBM Corp). The KolmogorovSmirnov was used to verify the normality of distribution of variables. Quantitative data were described using mean and standard deviation. Comparisons between groups for categorical variables were assessed using Chi-square test (Fisher Exact or Monte Carlo). Student t-test was used to compare two categories for normally distributed quantitative variables. Significance of the obtained results was judged at the $5 \%$ level.

\section{Results}

\section{Study sample}

Among 24 patients who underwent surgical resection of VS tumors 13 were females (54.2\%) and 11 were males (45.8\%) . The age of the patients ranged from 26 to 65 years with a mean of $46.8 \pm 12.7$ years. The selected patients had tumor sizes ranging from 31 mm up to $58 \mathrm{~mm}$ with a mean of $39 \pm 7 \mathrm{~mm}$. Tumors were right sided in 12 patients (50\%) and left sided in 12 patients (50\%). Tumors were approached through the retrosigmoid (RS) approach in all patients (100\%).

\section{Intraoperative trigeminal and facial nerve monitoring}

The trigeminal nerve was stimulated at the superior surface of the tumor in $24(100 \%)$ patients with a current intensity between 0.2 and 0.4 $\mathrm{mA}$. The mean latency of the recorded CMAP from the masseter muscle was $3.6 \pm 0.5 \mathrm{msec}$, while the mean latencies of the simultaneously recorded responses from the frontalis, o.oculi, nasalis, o.oris and mentalis recording channels were $4.6 \pm 0.9,4.1 \pm 0.7,3.9$ $\pm 0.4,4.3 \pm 0.8$ and $4.5 \pm 0.6 \mathrm{msec}$ respectively. The latencies of the recorded responses from the various facial nerve monitoring channels were all less than $6 \mathrm{msec}$ in duration and were therefore considered volume conducted responses associated with trigeminal nerve stimulation (Table 1, Figure 1-A). The frequency of the simultaneously recorded volume conducted responses associated with trigeminal nerve stimulation varied among facial nerve innervated muscles, and were observed on the frontalis, o.oculi, nasalis, o.oris and mentalis channels in 12 (50\%), 17 (70.8\%), 5 (20.8\%), 7 (29.2\%) and 4 (16.7\%) patients respectively (Table 1).

Further mapping of the superior surface of the tumor with the same current intensity in 6 (25\%) patients resulted in a different recorded pattern that consisted of a response recorded from the masseter muscle having a mean latency of $3.3 \pm 0.3$ msec which was not different from the previously response from the same muscle $(p=0.214)$ and was defined as a CMAP due to trigeminal nerve stimulation. In addition, there were simultaneously recorded responses from the facial nerve monitoring channels having mean latencies of $6.5 \pm 1.3,5.0$ $\pm 1.5,7.5 \pm 1.3,7.4 \pm 0.6$ and $7.0 \pm 1.5$ msec from the frontalis, o.oculi, nasalis, o.oris and mentalis muscles respectively. These responses 
were significantly longer in latency from the frontalis, nasalis, o.oris and mentalis muscles than the previously recorded volume conducted responses from the same muscles $(p=0.002 ; p=0.001 ; p<0.001$; and $p=0.015$ respectively) (Table 1$)$. Nevertheless, the mean latency of the response from the o.oculi in this pattern was not statistically different from the volume conducted response recorded from the same muscle $(p=0.244)$. It is worth noting that the o.oculi muscle was observed to have the highest number of volume conduction responses when the trigeminal nerve was stimulated.

Detailed analysis of the recorded CMAPs recorded from the facial nerve innervated muscles in those 6 patients showed variability in latency measurement between muscles. Therefore, to confirm that the facial nerve was simultaneously stimulated with the trigeminal nerve and to define the resulting pattern, the number of muscles having a CMAP with a latency of $7 \mathrm{msec}$ or more (confirming definite facial nerve stimulation) were assessed in each patient (Table 2: patients 1-6). When a response from the masseter muscle having a latency of less than $5 \mathrm{msec}$ (due to trigeminal nerve stimulation), was simultaneously recorded with a response from at least one of the five facial nerve monitoring channels having a latency of $7 \mathrm{msec}$ or more (due to facial nerve stimulation) the resulting pattern was named "trigemino-facial EMG response" (Figure 1-B).

During surgery the facial nerve course was anatomically identified as AC in $10(41.7 \%)$ and Al in $6(25 \%)$, AS in 8 (33.3\%), patients. The facial nerve in all 6 patients showing a trigemino-facial EMG response was anatomically confirmed later during the course of surgery to be displaced in an AS direction. However, among the 8 patients displaying an AS course of the facial nerve anatomically, 2 patients did not show an electrophysiologic trigemino-facial EMG response (Table 3). Mapping of the superior surface of the tumor in those 2 patients resulted in CMAPs having latencies of $7 \mathrm{msec}$ or more from facial nerve monitoring channels (4 out of 5 and 5 out of 5 facial muscles), and was not associated with a CMAP recorded from the masseter muscle, a pattern indicating direct facial nerve stimulation at the superior surface of the tumor (Table 2: patients 7\&8) (Figure 1-C). The facial nerve was found anatomically to be displaced at a higher plane that separated it from the trigeminal nerve and was in closer proximity to the stimulator in those 2 patients.

The facial nerve was stimulated at the end of surgery at the root exit zone in all patients at $2 \mathrm{~mA}$. The latency of the responses from the frontalis, o.oculi, nasalis and o.oris muscles were significantly shorter in the 6 patients who displayed a trigemino-facial EMG response compared to the latencies from the same muscles recorded from other patients $(p=<0.001 ; p=0.001 ; p=0.019$; and $p=0.010$ respectively). Results indicated that the CMAP measured at the end of surgery in these patients is not purely due to facial nerve stimulation but has volume conducted contributions. In addition, the latency of the responses from the mentalis muscle were shorter in the patients displaying the same pattern than the rest of the patients however, results did not reach statistical significance $(p=0.171)$ (Table 4$)$. It is worth noting that the mentalis muscle had the least number of volume conducted responses when the trigeminal nerve was stimulated.

\section{Surgical results and relation to postoperative outcome}

The degree of adhesion between the tumor capsule and the facial nerve just medial to the porus was described as weak in 4 (16.7\%), intermediate in $9(37.5 \%)$ and strong in $11(45.8 \%)$ patients [9]. Gross total tumor removal was achieved in $18(75 \%)$ patients; near total removal (a maximum $2 \mathrm{~mm}$ layer of tumor capsule was left behind at the site of maximal adhesion to the facial nerve ) was achieved in 4 (16.7\%) patients; and a subtotal removal was performed in $2(8.3 \%)$ patients [6]. The relation between facial nerve course, the degree of adhesion and degree of tumor removal are shown in Table 5. The immediate postoperative facial nerve outcome was grade I \& II in 12 (50\%) patients; grade III \& IV in 7 (29.2\%) patients; and grade V \& VI in $5(20.8 \%)$ patients. The long-term postoperative outcome was grade I \& II in 17 (70.8\%) patients; grade III \& IV in 7 (29.2\%) patients; and none of the patients had grade V \& VI long term postoperative outcome. The relation between facial nerve course, immediate and long term post-operative outcomes are shown in Table 5.

\section{Discussion}

Tumor size is one of the fundamental factors that influence postoperative facial nerve function during VS resection [15,24]. The facial nerve in large and giant VS is often stretched, thinned and splayed over the tumor surface as a result it becomes more vulnerable to injury $[18,20]$. Moreover, the nerve may be displaced into unusual positions by the effect of tumor growth rendering its localization a difficult task [4]. In the present study the facial nerve course was anatomically identified as AC in $10(41.7 \%)$ Al in 6 (25\%) and AS in 8 (33.3 \%) patients. The early identification of the AS course of the facial nerve may allow modification of the surgical strategy in favor of preservation of this critical structure.

Triggered EMG is used to map the surface of the tumor to confirm that the facial nerve is not in an area to be dissected. Once accessible in the surgical field, electric stimulation is used to assess the functional integrity of the nerve and to predict postoperative facial nerve outcome [1]. However, to our knowledge the use of triggered EMG for the early identification of an AS displaced facial nerve before being visualized in the surgical field has not been exploited yet. The trigeminal nerve was stimulated at the superior surface of the tumor in 24 
(100\%) patients, in addition further mapping of the superior surface of the tumor in 6 (25\%) patients before the facial nerve was anatomically visualized resulted in a CMAP recorded from the masseter muscle having a mean latency of 3.28 msec indicating stimulation of the trigeminal nerve, together with a CMAP having a latency of 7 msec or more from at least one of the facial nerve innervated muscles confirming simultaneous stimulation of the facial nerve. This pattern was termed the "trigemino-facial EMG response" and was attributed to the simultaneous stimulation of both the facial and trigeminal nerves at the superior surface of the tumor due to close proximity of both nerve to the stimulating probe. A situation that would occur if the facial nerve is anatomically displaced anterior and superiorly close to the trigeminal nerve. All of those 6 patients were later confirmed anatomically to have an AS displaced facial nerve once it was visible in the surgical field. On the other hand, not all patients with an AS displaced facial nerve showed a trigemino-facial EMG response. Nevertheless, the electrophysiological identification of an AS displaced facial nerve was still possible. Mapping the superior surface of the tumor in two patients resulted in a facial nerve response without simultaneous trigeminal nerve stimulation as the facial nerve was found to be displaced superiorly and at a higher plane that separated it from the trigeminal nerve by the effect of a giant tumor.

The early electrophysiological identification of the superior course of the facial nerve allowed removing the bulk of the tumor away from the nerve followed by progressive meticulous dissection along the plane of the facial nerve near the porus. The post-operative facial nerve outcome was not significantly different between the three facial nerve courses in the immediate or long-term period, despite the presence of strong adhesions in $75 \%$ of the patients with an AS course compared to $30 \%$ and $33 \%$ of patients with AC and Al displacements respectively (Table 5). Thus, it is crucial to locate the AS course of the facial nerve as early as possible to plan the progression of surgery and accomplish tumor removal with maximum functional preservation. Esquia-Medina et al argued that the displacement patterns of the facial nerve may impact postoperative facial nerve function [9]. They found that the Al and AC facial nerve displacements were associated with a better postoperative facial nerve function than the AS course. This may be attributed to the higher incidence of strong facial nerve adhesions (85\%) in patients with AS displaced nerves in their series, compared to those with Al (31\%), and AC (20\%) displaced nerves. The early identification of the facial nerve in the present work may be a reason why the patients with AS course did not have a worse outcome despite the more challenging resection in those patients.

Recognizing the electrophysiologic characteristics of the trigemino-facial EMG response is not only of value for the early identification of the AS course of the facial nerve; but it is also important for the neurophysiologist to be aware of this response when the facial nerve is displaced in a superior direction. If not detected it may be misinterpreted as a response due to trigeminal nerve stimulation only, giving the surgeon the false impression that the facial nerve is not at the superior surface of the tumor which may jeopardize this critical structure during the early stages of resection. It should be noted though that identification of the trigemino-facial EMG response may require some experience, since both the trigeminal and facial nerves are being stimulated simultaneously; the recorded CMAPs from the facial nerve muscles have volume conducted contributions (from the contracting trigeminal nerve innervated muscles) which make the latencies variable and may be overlooked as volume conducted responses.

In addition, knowledge of the trigemino-facial EMG response is also important when assessing the functional integrity of the facial nerve at the end of surgery by proximal stimulation using a supramaximal current intensity [5]. With supramaximal stimulation of an AS displaced facial nerve, current may spread to stimulate the nearby trigeminal nerve, leading to simultaneous contraction of the masseter and temporalis muscles. In this situation the CMAPs recorded from the muscles supplied by the facial nerve are not purely due to facial nerve stimulation but are likely to have contributions from the peripheral volume conducted responses; a condition that can be suspected if the latencies of the CMAPs are shorter than those of the usual proximal facial nerve stimulation and are associated with a simultaneous trigeminal nerve stimulation response. This problem may be one of the reasons why predictive methods for assessment of the facial nerve functional integrity show variability among different studies $[5,19,21]$. It is therefore critical to analyze facial nerve EMG data within context of the trigeminal nerve data for more accurate analysis.

In conclusion, understanding the trigemino-facial EMG response is important to assist in identifying an AS displaced facial nerve before it is visible in the surgical field to direct the dissection away from the nerve; to avoid electrophysiological confusion between the trigeminal nerve and the facial nerves which may provide misleading information to the surgeon; and to help detect if a measured CMAP to facial nerve stimulation at the end of surgery has volume conducted contributions from the trigeminal nerve.

\section{Declarations}

\section{Funding}

The authors have no relevant financial or non-financial interests to disclose 


\section{Conflict of interest}

The authors have no conflicts of interest to declare that are relevant to the content of this article

\section{Availability of data and material}

The Authors affirm that this manuscript is an honest, accurate, and transparent account of the study being reported; that no important aspects of the study have been omitted; and that any discrepancies from the study as planned have been explained.

\section{Code availability}

All authors confirm that all data and materials as well as software application or custom code support their published claims and comply with field standards.

\section{Authors' contributions}

All authors contributed to the study conception and design. Material preparation, data collection and analysis were performed by Yasmine A. Ashram, Youssef M. Zohdy, Tarek A. Rayan and Mohamed M. K. Badr-El-Dine. The first draft of the manuscript was written by Yasmine A. Ashram and Mohamed M. K. Badr-El-Dine, and all authors commented on previous versions of the manuscript. All authors read and approved the final manuscript.

\section{Ethics approval}

This study was performed in line with the principles of the Declaration of Helsinki. Approval was granted by the Ethics Committee of the University of Alexandria, Egypt (No. 0305049).

\section{Consent to participate}

Informed consent was obtained from all individual participants included in the study.

\section{Consent for publication}

The authors affirm that human research participants provided informed consent for publication.

\section{References}

1. Acioly MA, Liebsch M, de Aguiar PH, Tatagiba M (2013) Facial nerve monitoring during cerebellopontine angle and skull base tumor surgery: a systematic review from description to current success on function prediction. World Neurosurg 80(6):e271-300. https://doi.org/10.1016/j.wneu.2011.09.026

2. Ashram YA, Badr-El-Dine MMK (2014) Multichannel Facial Nerve Monitoring: Value in Detection of Mechanically Elicited Electromyographic Activity and Prediction of Postoperative Outcome. Otol Neurotol 35(7):1290-7. https://doi.org/10.1097/MA0.0000000000000441

3. Ashram YA, Yingling CD (2021) Intraoperative Monitoring of Cranial Nerves in Neurotologic Surgery. In: Flint PW, Haughey BH, Lund VJ, Robbins KH, Thomas JR, Lesperance MM, Francis H (ed) Cummings Otolaryngology Head and Neck Surgery 7th edn. Elsevier, Philadelphia, pp 2729-45

4. Bae CW, Cho YH, Hong SH, Kim JH, Lee JK, Kim CJ (2007) The anatomical location and course of the facial nerve in vestibular schwannomas : a study of 163 surgically treated cases. J Korean Neurosurg Soc 42(6):450-4.

https://doi.org/10.3340/jkns.2007.42.6.450

5. Bernat I, Grayeli AB, Esquia G, Zhang Z, Kalamarides M, Sterkers O (2010) Intraoperative electromyography and surgical observations as predictive factors of facial nerve outcome in vestibular schwannoma surgery. Otol Neurotol 31(2):306-12. https://doi.org/10.1097/MA0.0b013e3181be6228

6. Bloch DC, Oghalai JS, Jackler RK, Osofsky M, Pitts LH (2004) The fate of the tumor remnant after less-than-complete acoustic neuroma resection. Otolaryngol Head Neck Surg 130:104-12. https://doi.org/10.1016/S0194-5998(03)01598-5 
7. Deletis V, Urriza J, Ulkatan S, Fernandez-Conejero I, Lesser J, Misita D (2009) The feasibility of recording blink reflexes under general anesthesia. Muscle Nerve 39(5):642-6. https://doi.org/10.1002/mus.21257

8. Dong CC, Macdonald DB, Akagami R, Westerberg B, Alkhani A, Kanaan I, et al (2005) Intraoperative facial motor evoked potential monitoring with transcranial electrical stimulation during skull base surgery. Clin Neurophysiol 116(3):588-96.

https://doi.org/10.1016/j.clinph.2004.09.013

9. Esquia-Medina GN, Grayeli AB, Ferrary E, Tubach F, Bernat I, Zhang Z, et al (2009) Do facial nerve displacement pattern and tumor adhesion influence the facial nerve outcome in vestibular schwannoma surgery? Otol Neurotol 30(3):392-7.

https://doi.org/10.1097/MA0.0b013e3181967874

10. Harper CM, Daube JR (1998) Facial nerve electromyography and other cranial nerve monitoring. J Clin Neurophysiol 15(3):206-16. https://doi.org/10.1097/00004691-199805000-00004

11. House JW (1983) Facial nerve grading systems. Laryngoscope 93(8):1056-69. https://doi.org/10.1288/00005537-198308000-00016

12. Karkas A, Lamblin E, Meyer M, Gay E, Ternier J, Schmerber S (2014) Trigeminal nerve deficit in large and compressive acoustic neuromas and its correlation with MRI findings. Otolaryngol Head Neck Surg 151(4):675-80.

https://doi.org/10.1177/0194599814545440

13. Kircher ML, Kartush JM (2012) Pitfalls in intraoperative nerve monitoring during vestibular schwannoma surgery. Neurosurg Focus 33(3):E5. https://doi.org/10.3171/2012.7.FOCUS12196

14. Koos WT, Day JD, Matula C, Levy DI (1998) Neurotopographic considerations in the microsurgical treatment of small acoustic neurinomas. J Neurosurg 88(3):506-12. https://doi.org/10.3171/jns.1998.88.3.0506

15. Liu S, Jiang W, Zhang H, Li X, Wan X, Emmanuel B, et al (2015) Intraoperative neuromonitoring for removal of large vestibular schwannoma: Facial nerve outcome and predictive factors. Clin Neurol Neurosurg 133:83-9. https://doi.org/10.1016/j.clineuro.2015.03.016

16. Mastronardi L, Cacciotti G, Roperto R, Di Scipio E, Tonelli MP, Carpineta E (2016) Position and Course of Facial Nerve and Postoperative Facial Nerve Results in Vestibular Schwannoma Microsurgery. World Neurosurg 94:174-80. https://doi.org/10.1016/j.wneu.2016.06.107

17. Minahan RE, Mandir AS (2011) Neurophysiologic intraoperative monitoring of trigeminal and facial nerves. J Clin Neurophysiol 28(6):551-65. https://doi.org/10.1097/WNP.0b013e318241de1a

18. Samii M, Gerganov VM, Samii A (2010) Functional outcome after complete surgical removal of giant vestibular schwannomas. J Neurosurg 112(4):860-7. https://doi.org/10.3171/2009.7.JNS0989

19. Sughrue ME, Kaur R, Kane AJ, et al (2010) The value of intraoperative facial nerve electromyography in predicting facial nerve function after vestibular schwannoma surgery. J Clin Neurosci 17(7):849-52. https://doi.org/10.1016/j.jocn.2010.02.003

20. Torres R, Nguyen Y, Vanier A, Smail M, Ferrary E, Sterkers O, et al (2017) Multivariate analysis of factors influencing facial nerve outcome following microsurgical resection of vestibular schwannoma. Otolaryngol Head Neck Surg 156(3):525-33. https://doi.org/10.1177/0194599816677711

21. Turel MK, Babu KS, Singh G, Chacko AG (2014) The utility of facial nerve amplitude and latency ratios in predicting postoperative facial nerve function after vestibular schwannoma surgery. Neurol India 62(2):178-82. https://doi.org/10.4103/0028-3886.132373

22. Vivas EX, Carlson ML, Neff BA, Shepard NT, McCracken DJ, Sweeney AD, et al (2018) Congress of Neurological Surgeons Systematic Review and Evidence-Based Guidelines on Intraoperative Cranial Nerve Monitoring in Vestibular Schwannoma Surgery. Neurosurgery 82(2):E44-E46. https://doi.org/10.1093/neuros/nyx513

23. Yingling CD, Gardi JN (2008) Intraoperative monitoring of facial and cochlear nerves during acoustic neuroma surgery. Neurosurg Clin N Am 19(2):289-315. https://doi.org/10.1016/j.nec.2008.02.011 
24. Zou P, Zhao L, Chen P, Xu H, Liu N, Zhao P, et al (2014) Functional outcome and postoperative complications after the microsurgical removal of large vestibular schwannomas via the retrosigmoid approach: a meta-analysis. Neurosurg Rev 37(1):15-21.

https://doi.org/10.1007/s10143-013-0485-7

\section{Tables}

Table 1. Description and comparison between the latencies of the CMAPs and volume conducted responses of the response to trigeminal nerve stimulation and the trigemino-facial response

$\begin{array}{ll}\begin{array}{l}\text { Patients with trigeminal nerve stimulation } \\ \text { response }(n=24)\end{array} & \text { Patients with trigemino-facial response } \\ (n=6) & \mathbf{t} \quad \mathbf{p}\end{array}$

\begin{tabular}{|c|c|c|c|c|c|c|c|c|c|c|}
\hline \multirow[t]{2}{*}{ Muscle } & \multirow{2}{*}{$\begin{array}{l}\text { Number } \\
(\%)\end{array}$} & \multicolumn{2}{|c|}{ Latency } & \multirow[t]{2}{*}{ Description } & \multirow{2}{*}{$\begin{array}{l}\text { Number } \\
(\%)\end{array}$} & \multicolumn{2}{|c|}{ Latency } & \multirow[t]{2}{*}{ Description } & & \\
\hline & & Range & $\begin{array}{l}\text { Mean } \pm \\
\text { SD }\end{array}$ & & & Range & $\begin{array}{l}\text { Mean } \pm \\
\text { SD }\end{array}$ & & & \\
\hline Masseter & $24(100 \%)$ & $\begin{array}{l}2.7- \\
4.4\end{array}$ & $\begin{array}{l}3.6 \pm \\
0.5\end{array}$ & CMAP & $6(100 \%)$ & $\begin{array}{l}2.8- \\
3.8\end{array}$ & $3.3 \pm 0.3$ & CMAP & 1.272 & 0.214 \\
\hline Frontalis & $12(50 \%)$ & $\begin{array}{l}2.8- \\
5.8\end{array}$ & $\begin{array}{l}4.6 \pm \\
0.9\end{array}$ & $\begin{array}{l}\text { Volume } \\
\text { Conduction }\end{array}$ & $6(100 \%)$ & $\begin{array}{l}4.5- \\
7.5\end{array}$ & $6.5 \pm 1.3$ & CMAP & $3.764^{\star}$ & $0.002^{*}$ \\
\hline O. Oculi & $17(70.8 \%)$ & $\begin{array}{l}3.1- \\
5.4\end{array}$ & $\begin{array}{l}4.1 \pm \\
0.7\end{array}$ & & $6(100 \%)$ & $\begin{array}{l}3.3- \\
6.8\end{array}$ & $5.0 \pm 1.5$ & & 1.298 & 0.244 \\
\hline Nasalis & $5(20.8 \%)$ & $\begin{array}{l}3.3- \\
4.3\end{array}$ & $3.9 \pm 0.4$ & & $6(100 \%)$ & $\begin{array}{l}6.4- \\
9.5\end{array}$ & $7.5 \pm 1.3$ & & $6.281^{*}$ & $0.001^{*}$ \\
\hline O. Oris & $7(29.2 \%)$ & $\begin{array}{l}3.1- \\
5.9\end{array}$ & $4.3 \pm 0.8$ & & $6(100 \%)$ & $\begin{array}{l}6.6- \\
8.5\end{array}$ & $7.4 \pm 0.6$ & & $7.609^{*}$ & $<0.001^{*}$ \\
\hline Mentalis & $4(16.7 \%)$ & $\begin{array}{l}3.9- \\
5.4\end{array}$ & $4.5 \pm 0.6$ & & $6(100 \%)$ & $\begin{array}{l}5.2- \\
9.6\end{array}$ & $7.0 \pm 1.5$ & & $3.084^{*}$ & $0.015^{*}$ \\
\hline \multicolumn{11}{|c|}{$\mathrm{p}$ : $\mathrm{p}$ value for } \\
\hline \multicolumn{11}{|c|}{ t: Student t-test } \\
\hline \multicolumn{11}{|c|}{ *: Statistically significant at $p \leq 0.05$} \\
\hline \multicolumn{11}{|c|}{ CMAP: Compound muscle action potential } \\
\hline
\end{tabular}

Table 2. Latencies of the CMAPs on the masseter and facial nerve monitoring channels in 8 patients with an anatomically confirmed superior course of the facial nerve

\begin{tabular}{|c|c|c|c|c|c|c|c|c|}
\hline \multirow[b]{2}{*}{ Patient } & \multicolumn{6}{|l|}{ Muscle } & \multirow[t]{2}{*}{ Number of FN muscles $\geq 7 \mathrm{msec}$} & \multirow[t]{2}{*}{ Pattern } \\
\hline & Masseter & Frontalis & O. Oculi & Nasalis & O. Oris & Mentalis & & \\
\hline 1 & 3.83 & 7.40 & 6.78 & 8.84 & 7.56 & 7.66 & 4 & \multirow{6}{*}{$\begin{array}{l}\text { Trigemino-facial } \\
\text { EMG response }\end{array}$} \\
\hline 2 & 2.80 & 4.50 & 3.50 & 6.90 & 7.10 & 6.20 & 1 & \\
\hline 3 & 3.35 & 5.40 & 4.09 & 9.54 & 8.49 & 9.60 & 3 & \\
\hline 4 & 3.20 & 7.50 & 5.80 & 6.40 & 6.60 & 5.20 & 1 & \\
\hline 5 & 3.29 & 7.10 & 6.42 & 6.89 & 7.40 & 6.89 & 2 & \\
\hline 6 & 3.33 & 7.16 & 3.33 & 6.47 & 7.45 & 6.57 & 2 & \\
\hline 7 & NR & 14.2 & 8.2 & 9.02 & 10.4 & 12.06 & 5 & \multirow{2}{*}{$\begin{array}{l}\text { Facial nerve } \\
\text { response }\end{array}$} \\
\hline 8 & 8.05 & 8.55 & 7.14 & 6.94 & 7.6 & 7.6 & 4 & \\
\hline
\end{tabular}




\begin{tabular}{|c|c|c|c|c|}
\hline \multirow[b]{2}{*}{ Trigemino-facial EMG response } & \multicolumn{2}{|c|}{ Facial nerve course (AS) } & \multirow[t]{2}{*}{$c^{2}$} & \multirow[t]{2}{*}{$\mathrm{FE}_{\mathrm{p}}$} \\
\hline & Yes $(n=8)$ & No $(n=16)$ & & \\
\hline Yes $(n=6)$ & $6(100 \%)$ & $0(0 \%)$ & \multirow[t]{2}{*}{$16.000^{*}$} & \multirow[t]{2}{*}{$<0.001^{*}$} \\
\hline No $(n=18)$ & $2(11.1 \%)$ & $16(88.9 \%)$ & & \\
\hline \multicolumn{5}{|l|}{$c^{2}$ : Chi square test } \\
\hline \multicolumn{5}{|l|}{ FE: Fisher Exact } \\
\hline \multicolumn{5}{|c|}{$\mathrm{p}: \mathrm{p}$ value for comparing between the studied categories } \\
\hline \multicolumn{5}{|c|}{ *: Statistically significant at $p \leq 0.05$} \\
\hline
\end{tabular}

Table 4. Comparison between the latency of the response recorded after supramaximal proximal stimulation at the end of surgery between the patients who displayed a trigemino-facial EMG response and all other patients included in the study

\begin{tabular}{|c|c|c|c|c|}
\hline \multirow[t]{2}{*}{ Muscle } & $\begin{array}{l}\text { Patients displaying a Trigemino-facial EMG response } \\
(n=6)\end{array}$ & $\begin{array}{l}\text { Other patients } \\
(\mathrm{n}=18)\end{array}$ & \multirow[t]{2}{*}{$\mathrm{t}$} & \multirow[t]{2}{*}{$\mathrm{p}$} \\
\hline & Mean $\pm S D$ & Mean \pm SD & & \\
\hline Masseter & $3.7 \pm 1.7$ & $6.8 \pm 0.7$ & $4.385^{\star}$ & $0.005^{*}$ \\
\hline Frontalis & $4.9 \pm 1.4$ & $8.6 \pm 1.9$ & $4.509^{*}$ & $<0.001^{*}$ \\
\hline Oculi & $4.4 \pm 2.1$ & $7.2 \pm 1.3$ & $3.854^{*}$ & $0.001^{*}$ \\
\hline Nasalis & $5.5 \pm 2.1$ & $7.4 \pm 1.2$ & $2.553^{*}$ & $0.019^{*}$ \\
\hline Oris & $5.6 \pm 1.6$ & $7.6 \pm 1.5$ & $2.799^{\star}$ & $0.010^{*}$ \\
\hline Mentalis & $6.4 \pm 1.8$ & $7.5 \pm 1.7$ & $1.415^{\star}$ & 0.171 \\
\hline \multicolumn{5}{|c|}{ t: Student t-test } \\
\hline \multicolumn{5}{|c|}{$p: p$ value for comparing between the studied categories } \\
\hline \multicolumn{5}{|c|}{ *: Statistically significant at $p \leq 0.05$} \\
\hline
\end{tabular}


Table5. Relation between the facial nerve course, the degree of adhesion, degree of tumor removal, immediate and long-term facial nerve function.

\begin{tabular}{|c|c|c|c|c|c|c|}
\hline & \multicolumn{6}{|c|}{ Facial nerve course } \\
\hline & \multirow{2}{*}{$\begin{array}{l}A C \\
(n=10)\end{array}$} & \multirow{2}{*}{$\begin{array}{l}\text { Al } \\
(n=6)\end{array}$} & \multirow{2}{*}{$\begin{array}{l}\text { AS } \\
(n=8)\end{array}$} & \multirow{2}{*}{$\begin{array}{l}\text { Total } \\
(n=24)\end{array}$} & \multirow[t]{3}{*}{$c^{2}$} & \multirow{3}{*}{${ }^{M C} C_{p}$} \\
\hline & & & & & & \\
\hline & Number (\%) & Number (\%) & Number (\%) & Number (\%) & & \\
\hline \multicolumn{7}{|l|}{ Adhesions } \\
\hline Weak & $3(30 \%)$ & $1(16.7 \%)$ & $0(0 \%)$ & $4(16.7 \%)$ & \multirow[t]{3}{*}{4.829} & \multirow[t]{3}{*}{0.296} \\
\hline Intermediate & $4(40 \%)$ & $3(50 \%)$ & $2(25 \%)$ & $9(37.5 \%)$ & & \\
\hline Strong & $3(30 \%)$ & $2(33.3 \%)$ & $6(75 \%)$ & $11(45.8 \%)$ & & \\
\hline \multicolumn{7}{|l|}{ Tumor removal } \\
\hline Total & $8(80 \%)$ & $5(83.3 \%)$ & $5(62.5 \%)$ & $18(75 \%)$ & \multirow[t]{3}{*}{1.991} & \multirow[t]{3}{*}{0.942} \\
\hline Near-total & $1(10 \%)$ & $1(16.7 \%)$ & $2(25 \%)$ & $4(16.7 \%)$ & & \\
\hline Subtotal & $1(10 \%)$ & $0(0 \%)$ & $1(12.5 \%)$ & $2(8.3 \%)$ & & \\
\hline \multicolumn{7}{|c|}{ Immediate post-operative outcome } \\
\hline Good (I\&II) & $5(50 \%)$ & $4(66.7 \%)$ & $3(37.5 \%)$ & $12(50 \%)$ & \multirow[t]{3}{*}{4.265} & \multirow[t]{3}{*}{0.408} \\
\hline Intermediate (III\&IV) & $4(40 \%)$ & $0(0 \%)$ & $3(37.5 \%)$ & $7(29.2 \%)$ & & \\
\hline Bad (V\&VI) & $1(10 \%)$ & $2(33.3 \%)$ & $2(25 \%)$ & $5(20.8 \%)$ & & \\
\hline \multicolumn{7}{|c|}{ Long term post-operative outcome } \\
\hline Good (I\&II) & $8(80 \%)$ & $4(66.7 \%)$ & $5(62.5 \%)$ & $17(70.8 \%)$ & \multirow[t]{3}{*}{0.911} & \multirow[t]{3}{*}{0.739} \\
\hline Intermediate (III\&IV) & $2(20 \%)$ & $2(33.3 \%)$ & $3(37.5 \%)$ & $7(29.2 \%)$ & & \\
\hline Bad (V\&VI) & $0(0 \%)$ & $0(0 \%)$ & $0(0 \%)$ & $0(0 \%)$ & & \\
\hline \multicolumn{7}{|l|}{$c^{2}:$ Chi square test } \\
\hline \multicolumn{7}{|l|}{ MC: Monte Carlo } \\
\hline $\mathrm{p}$ : $\mathrm{p}$ value for compa & udied categor & & & & & \\
\hline
\end{tabular}

\section{Figures}

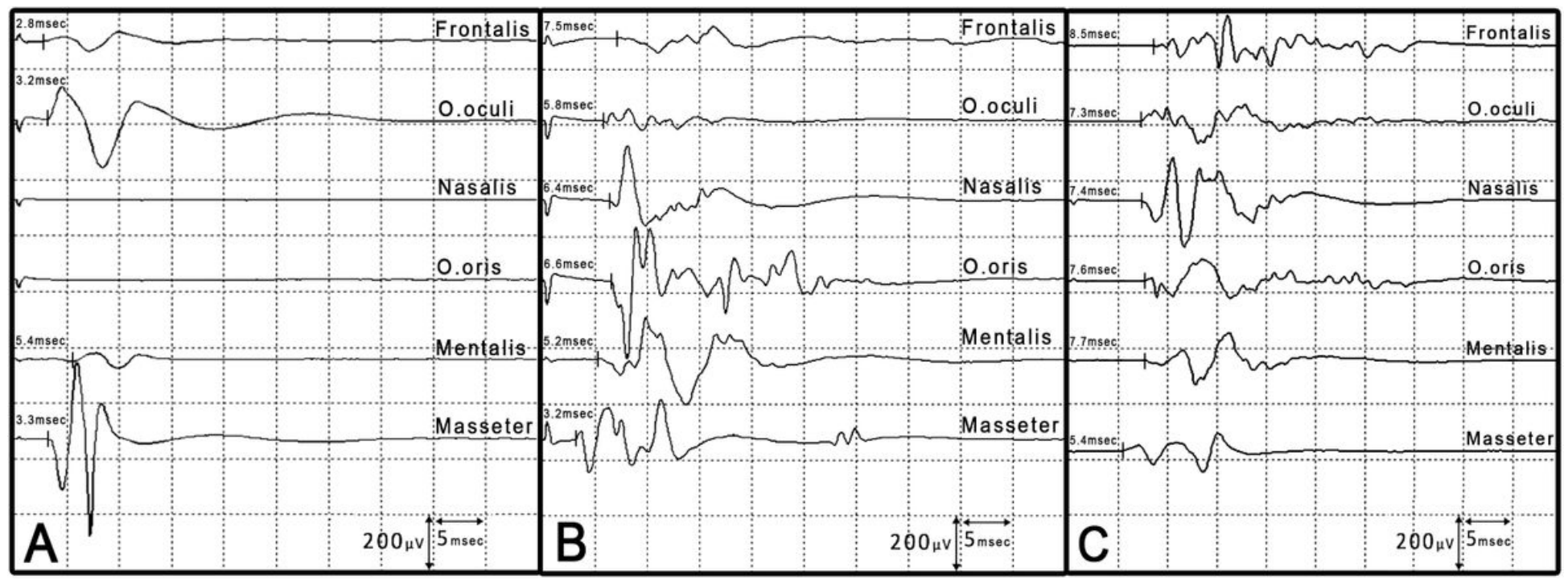




\section{Figure 1}

Three different patterns recorded after mapping the superior surface of the tumor at an intensity between $0.2-0.4 \mathrm{~mA}$. The vertical marker shown on every trace points to the latency of the recorded response. A. Traces showing a CMAP recorded from the masseter due to stimulation of the trigeminal nerve associated with volume conduction on the frontalis, o.oculi and mentalis muscles. B. Traces showing CMAP recorded from both the masseter and facial nerve monitoring channels due to simultaneous stimulation of the trigeminal nerve and the facial nerve (trigemino-facial EMG response). The variable latencies of the facial nerve CMAPs are due to the presence of volume conduction contributions. C. Traces showing CMAP recorded from the facial nerve monitoring channels due to facial nerve stimulation associated with a volume conduction response on the masseter muscles. 